\title{
LAPSIPERHEIDEN EROPALVELUIDEN KEHITTÄMINEN SOSIAALI- JA TERVEYSPALVELUJÄRJESTELMÄSSÄ
}

\author{
Niina Nurmela: VTM, sosiaalityön yliopisto-opettaja, Turun yliopisto \\ Anniina Kaittila: VTT, sosiaalityön yliopistonlehtori, Turun yliopisto \\ nanurm@utu.fi;sairai@utu.fi \\ Janus vol. 27 (4) 2019, 422-429
}

JOHDANTO

Lapsista yhä useampi kokee vanhempiensa eron. Vuonna 2017 avioeroon päättyi 13485 avioliittoa. Todellinen erojen määrä on kuitenkin huomattavasti suurempi, sillä avoliitossa tapahtuvia eroja ei rekisteröidä. (SVT 2018.) Ero on perheenjäsenille usein kriisi. Enemmistö selviää eron aiheuttamasta kriisistä kuitenkin hyvin omien tukiverkostojensa tai ulkopuolisen tuen avulla (esim. Kiiski 2011). Osa eroista ajautuu konfliktitilanteeseen, jossa lapsen asioista sopiminen vaikeutuu. Pitkittyessään erokonfliktilla on lapsen ja hänen perheensä elämään negatiivinen vaikutus. Tutkimukset osoittavat pitkittyneiden huoltajuusriitojen olevan psyykkisesti hyvin kuormittavia lapsille (Karttunen 2010; Amato ym. 2011) ja vanhemmille (Symoens ym. 2014; Sbarra 2015) sekä taloudellisesti kalliita (Hämäläinen 2011).

Erot kuormittavat myös sosiaali- ja terveydenhuoltojärjestelmää. Erojen vaikutukset näkyvät esimerkiksi terveydenhuollossa eron kokeneiden lasten ja vanhempien psyykkisenä pahoinvointina ja avun tarpeena. Sosiaalipalveluissa erojen vaikutukset tulevat esiin esimerkiksi perheneuvonnan, lastenvalvonnan ja lastensuojelun tuen tarpeena. Päivähoidossa ja koulussa lasten psyykkinen oireilu vanhempien eroon liitty-

en saattaa näkyä lasten käyttäytymisen muutoksena ja lisätuen tarpeena.

Apua eroaville tarjotaan useissa lakisääteisissä sekä niitä täydentävissä järjestöjen, seurakuntien ja yksityisten toimijoiden tuottamissa palveluissa. Sosiaalihuoltolaissa (1301/2014) kunnan vastuulle erotukeen liittyen on säädetty lapsen huoltoa ja tapaamisoikeutta koskevan päätöksen vahvistaminen, ratkaisemiseen liittyvät tehtävät, perheasioiden sovittelu, sosiaalityö, sosiaaliohjaus, kasvatus- ja perheneuvonta, perhetyö, kotipalvelu sekä vanhemman ja lapsen välisten tapaamisten valvonta. Myös avioliittolaissa (234/1929) on säädetty perheasioiden sovittelusta, jonka järjestämisestä huolehtii kunnan sosiaalitoimi. Lisäksi laissa lapsen huollosta ja tapaamisoikeudesta (1983/361) säädetään huolto- ja tapaamisriitojen tuomioistuinsovittelusta. Muiden toimijoiden tuottamina palveluina esimerkiksi seurakunnat tarjoavat keskusteluapua perheasiain neuvottelukeskuksissa, järjestöt vastaanotto-, sähköisiä ja kurssimuotoisia palveluita ja yksityiset toimijat terapiapalveluita.

Eronneiden ja eroa harkitsevien perheiden palveluissa on nostettu viime vuosina esiin useita haasteita liittyen palveluiden saatavuuteen, oikea-aikaisuuteen sekä sisältöön. Jonotusajat ovat pitkiä, erilaiset tukimuodot ovat irral- 
laan toisistaan ja perheet joutuvat toisinaan hakemaan apua useista paikoista ja useita kertoja. Palvelujen saatavuus vaihtelee kunnittain ja palvelun toteuttamista ohjaavien viitekehysten ja ammatillisten osaamisvaatimusten määrittely on puutteellista (ks. esim. Alppivuori 2017).

Kannanottoja eropalvelujen kehittämiseksi on viime vuosina tehty useilta tahoilta. Lapsiasiainvaltuutettu, Lastensuojelun Keskusliitto ja Väestöliitto tekivät jo vuonna 2010 aloitteen (Lapsen paras etusijalle eropalveluissa, 2010), jossa todettiin tarve kansallisille linjauksille eropalvelujen kehittämisessä. Tavoitteena oli vaikuttaa eron hoitamiseen lapsen edun mukaisella tavalla sekä varhaisen tukemisen, sovittelevan työotteen ja eri tahojen välisen vuoropuhelun painottumiseen eropalveluissa. Myös YK:n Lapsen oikeuksien komitea on antanut Suomelle suosituksen lisätä perheneuvontapalveluja eroa suunnitteleville vanhemmille ja varmistaa huoltajuusriidoissa lapsen edun toteutuminen. Eropalvelujen kehittäminen nostettiinkin yhdeksi Lapsi- ja perhepalvelujen muutosohjelman (LAPE) keskeisistä kehittämiskohteista.

Eron eri vaiheissa ilmenee avun tarvetta niin vanhemmilla kuin lapsillakin. Tässä puheenvuorossa esittelemme, millaisia avun ja tuen tarpeita lapsilla ja vanhemmilla on eroon liittyen, millaisiin teemoihin eropalvelujen kehittämisessä on tarpeen keskittyä sekä millaisia koulutuksellisia tarpeita siihen liittyy.

\section{EROKRIISI JA AVUNTARVE}

Eron käynnistäjinä mainitaan yleisimmin kommunikaatiovaikeudet, suhteen hoitamattomuus ja puolisosta vieraantuminen (Kiiski 2011; Cohen \& FinziDottan 2012), rakastuminen toiseen, liiton ulkopuolinen suhde, puolison väkivaltaisuus, kriittiset elämäntapahtumat ja arjen hallitsemattomuus (Bodenmann ym. 2007). Naiset toimivat miehï aloitteellisemmin hakiessaan avioeroa epätyydyttävästä liitosta (Auvinen 2006, 61; Kiiski 2011; Birditt ym. 2017).

Tapahtuupa ero suunniteltuna tai äkillisesti, liittyy siihen aina myös stressin ja luopumisen kokemuksia. Luopuminen parisuhteen yhteisestä tulevaisuudesta sisältää aina jonkinasteisen surutyön. Amato (2000) näkee erotilanteen aiheuttaman stressin liittyvän kiinteästi myös vanhemmuuden tehtävien uudelleenjakoon ja vastuun lisääntymiseen erityisesti sillä vanhemmalla, jonka luokse lapset jäävät asumaan. Lisäksi emotionaalisen ja taloudellisen tuen menetys sekä konfliktitilanteen syntyminen ex-puolisoiden välille lisäävät eron aiheuttamaa stressiä. Eron käsittelyyn vaikuttavat myös syy tai syyt, josta ero on aiheutunut. Toisinaan osapuolten käsitykset eron syistä voivat olla hyvin erilaiset.

Äkillinen psyykkinen kriisi, joksi parisuhteen päättyminen ja ero luetaan, horjuttaa yksilön voimavaroja ja vaikuttaa sopeutumiskykyyn (Henriksson \& Lönnqvist 2014). Castrén (2009) onkin kuvannut eroa ristipaineena, johon sisältyy kaksi vastakkaista odotusta liittyen yksilön eheytymiseen ja vastuulliseen vanhemmuuteen. Ero voi 
seurata mukana pitkään, riippuen siitä, missä perheen elinkaaren vaiheessa se on tapahtunut. Eron negatiiviset vaikutukset näkyvät somaattisina sairauksina, masennuksena, stressinä, pelkona sekä itsetunnon laskuna (Bracke ym. 2010; Isometsä 2011, 23). Mikäli ero on tullut eteen yllättäen, laukaisee se ihmisessä kriisireaktion, joka on luonnollinen keino sopeutua kestämättömään ja äkilliseen kuormitukseen (Henriksson \& Lönnqvist 2014). Erokriisin käsitteleminen on keskeistä toipumisessa. Kuitenkin erityisesti työstämättömän eron on nähty olevan yhteydessä hyvinvoinnin heikentymiseen.

Myös lapselle ero voi olla kriisi, sillä perhe toimii lapsen merkittävimpänä kehitys- ja ihmissuhdeympäristönä. Omien huolien sekä psyykkisen tai fyysisen voinnin heikentymisen takia vanhemmalla voi olla vaikeuksia nähdä ja kohdata lapsen tarpeita (Amato 2000). Lapsen sopeutuminen eroon on pitkälti riippuvaista vanhempien kyvystä huomioida lapsen tarpeet oman kriisinsä keskellä (Di Stefano \& Cyr 2014). Erokriisin keskellä voi myös olla haasteellista neuvotella lapsen huoltajuuteen, tapaamisiin tai elatukseen liittyvistä asioista lapsen etu huomioiden. Aina vanhemmat eivät välttämättä pysty sopimaan lapsen edun mukaisella tavalla, vaan tilanne ajautuu huoltoriidaksi. Lapsen elatukseen, tapaamisoikeuteen ja huoltoon liittyviä riita-asioita käsitellään oikeudessa noin 2000 tapausta vuosittain ja määrä on pysynyt kohtuullisen vakiona viime vuosina (esim. Hautanen 2017; OM 11/2018).

Huoltoriita, jossa vanhemmat eivät ole päässeet yksimielisyyteen lapsen huoltoon ja asumiseen liittyvistä kysymyk- sistä, on pitkään jatkuessaan stressitilanne ja selkeä riskitekijä mielenterveyden häiriöille (esim. Henriksson \& Lönnqvist 2014). Huoltoriita voi näyttäytyä vanhempien psyykkisenä, fyysisenä, sosiaalisena ja taloudellisena kuormituksena. Sen aikana toiseen vanhempaan voi kohdistua kontrollointia, manipulointia tai häirintää. Vanhempi voi kokea toisen vanhemman taholta uhkailua, painostamista, mitätöintiä, totuuden ja lasta koskevien asioiden tarkoituksellista salailua. Patologisissa eli pitkittyneissä huoltoriidoissa riita voi ilmetä myös toiseen vanhempaan kohdistuvana vainoamisena. Vainoaminen altistaa myös lapsen konfliktin negatiivisille vaikutuksille ja luo lapselle turvattomuutta (Nikupeteri ym. 2015). Huoltoriitoihin liittyy monesti lisäksi lapsen altistuminen lojaliteettiristiriidalle, mikä aiheuttaa lapselle suurta psyykkistä kuormitusta (esim. Karttunen 2010).

Huoltoriitojen yhteydessä on nostettu esiin myös lapsen vieraannuttaminen toisesta vanhemmasta. Vieraannuttamisessa vanhempi pyrkii omalla toiminnallaan estämään toisen vanhemman mahdollisuuden pitää yhteyttä lapseen (Häkkänen-Nyholm 2010; Garber 2014) ja lapsen suhde toiseen vanhempaan voi katketa täysin.Vieraannuttaminen on lapselle psyykkisesti vahingollista ja voi johtaa lapsen käyttäytymisen ja tunne-elämän häiriöihin. (Luoma \& Aronen 2016.) Vieraannuttamisen käsitettä (parental alienation syndrome) on myös laajasti kritisoitu (Dallam \& Silberg 2016; O’Donohue ym. 2016), sillä se voi olla passiivista, aktiivista, tiedostettua tai tiedostamatonta toimintaa vanhemman taholta. Suomessa lapsenhuoltolain uudistamista pohtinut 
työryhmä päätyi ehdottamaan uuteen lakiin lapsen huollosta ja tapaamisoikeudesta lisättäväksi säännöksen, jossa korostetaan, että vanhemman on kasvatustehtävässään vältettävä kaikkea, mikä on omiaan aiheuttamaan haittaa lapsen ja vanhemman väliselle suhteelle (LHL 361/1983, 2 ().

\section{Asiakastarpeet JA}

\section{ASIAKASLÄHTÖISYYS PALVELUJEN} KEHITTÄMISEN LÄHTÖKOHTANA

Aiemmissa tutkimuksissa eropalvelujen kehittämisen tarpeina on tuotu esiin matalan kynnyksen eroneuvonta sekä palvelujen takaaminen nopeasti ja tasa-arvoisesti asuinkunnasta riippumatta (Karvinen-Niinikoski \& Pelli 2010; Haavisto ym. 2014). Myös lapsen näkökulma on tarpeen tuoda aiempaa vahvemmin työskentelyn keskiöön. Lapsen näkökulman esille nostavan eroauttamisen on nähty lisäävän vanhempien yhteistyötä sekä lapsen tarpeiden huomioimista (Ballard ym. 2013; Greenberg ym. 2012). Myös vanhempien välistä yhteistyötä tukevat kurssit ja koulutukset sekä koko perheelle tarjottavien auttamismallien kehittäminen on nähty tärkeiksi eroauttamisen kehittämisen kohteiksi (Hämäläinen 2012). Oma tärkeä osa-alueensa on lapsille ja nuorille tarjottavan tuen vahvistaminen siten, että eron kokeneille lapsille tarjottaisiin matalan kynnyksen keskusteluapua esimerkiksi koulukuraattorin tarjoamana palveluna (Kauppinen 2013).

Eropalvelujen kehittämisessä tulee huomioida, että lapset, vanhemmat ja perheet voivat tarvita tukea aina harkintavaiheesta tilanteisiin, joissa van- hempien välillä on lapsen hyvinvointia vakavasti vaarantava huolto- ja tapaamisriita. Palvelujen kehittämistä tuleekin tarkastella jatkumona siten, että apua eroon on saatavissa erilaisissa elämäntilanteissa varhaisen vaiheen tuesta vaativiin palveluihin. Tätä huomioita tukee LAPE-muutosohjelman (Kohti lapsi- ja perhelähtöisïa palveluita) puitteissa mallinnettu lapsiperhepalvelujen järjestämisen rakenne, jossa palvelut on jaettu perhekeskustasoon (varhaisen tuen palvelut, kuten neuvola, kasvatusja perheneuvola), erityistasoon (lastensuojelu, lastenpsykiatria) sekä vaativaan tasoon (osaamis- ja tukikeskuksiin koottavat palvelut).

LAPE-muutosohjelmassa eropalvelujen kehittämisen erityisenä kohteena olivat eron ensiapupisteet, jossa vanhemmilla on mahdollisuus saada nopeasti oikeudellista neuvontaa ja tukea erotilanteissa, samoin vanhemmuussuunnitelma ja sähköiset palvelut (24/7 periaatteella toimivat palvelut, joiden kautta saa lisätietoa oman alueen palveluista). Lisäksi kehitettiin Ensi- ja turvakotien internetportaalia, johon on koottu tietoa eropalveluista (apuaeroon.fi) sekä tehtiin muuta kehittämistyötä liittyen esimerkiksi eropalvelujen työnsisältöihin ja tavoitteisiin. Eropalvelut huomioitiin erityisesti osana perhekeskusten kehittämistä. Maakunnallinen perhekeskus kokoaa kaikki perheen palvelut yhteen ja parantaa palvelujen tunnettavuutta sekä asiakkaiden ohjaamista heidän tilanteeseensa sopivan tuen piiriin (Bildjuschkin 2018). Myös vaativan tason osaamis- ja tukikeskuspalveluissa yhtenä keskeisenä tehtävänä on kehittää toimintamalleja ja tutkimusta vaativiin huolto- ja tapaamisriitoihin liittyen (Halila ym. 2019). 
Olennaista palvelujen kehittämisessä onkin tutkimuksen kytkeminen työn vaikuttavuuden arviointiin sekä eron kokeneiden perheiden elämäntilanteiden ymmärtämiseen. Eroon voi liittyä esimerkiksi väkivaltaa ja vieraannuttamista, joista tarvitaan lisätutkimusta ja tutkimusperustaista työkäytäntöjen kehittämistä.

\section{OSAAMISEN KEHITTÄMISEN TARPEET}

Eroauttamisen piirissä työntekijöiden taidoissa ja työskentelytavoissa voi olla suurta vaihtelua. Tämä voi johtua koulutuksen puutteesta sekä siitä, ettei esimerkiksi lastenvalvojan työhön ole määritelty tarkemmin koulutuksellisia ja osaamisvaatimuksia. ${ }^{1}$ Sekä asiakkaan että työntekijän kannalta on tärkeä määritellä, mitkä ovat työn osaamisvaatimukset ja millainen tietopohja työtä ohjaa. Osaamisvaatimuksilla voidaan varmistaa työn laatua sekä asiakkaan oikeusturvaa. Työkäytäntöjen kehittämisen näkökulmasta on tarpeen kiinnittää huomioita myös siihen, miten moniammatillisuutta ja eri koulutusten tuottamaa erityisosaamista pystyttäisiin parhaalla mahdollisella tavalla tuomaan asiakkaan hyödyksi. Suurissa kaupungeissa, kuten Helsingissä ja Turussa, perheoikeudellisia palveluja on alettu koota perheoikeudellisiin yksiköihin. Näihin yksiköihin on koottu muun muassa eroneuvontaa, olosuhdeselvitysten tekoa sekä lapsen huoltoon, tapaamiseen ja elatukseen liittyvien sopimusten laatimista. Perheoikeudellisten yksiköiden voidaan olettaa yleistyvän, mikäli maakuntauudistus etenee. Tällöin myös moniammatillinen, eri alojen osaamista yhdistävä työ mahdollistuu aiempaa paremmin. Psykososiaalisen ja juridisen eroneuvonnan ja kriisityön osaamisen yhdistäminen varmistaa, että asiakas saa tarvitsemaansa ammattitaitoista apua keskitetysti. Tärkeää on, että näihin palveluihin linkittyy myös muu kunnallinen sekä järjestöjen ja yksityisten toimijoiden tarjoama eroapu.

Eroon liittyvää koulutusta tulee toteuttaa sekä osana sosiaali- ja terveysalan peruskoulutusta että täydennyskoulutuksena. Riittävä ammatillinen tietoisuus eron aiheuttamasta kriisistä ja muutoksesta sekä vanhemmille että lapselle auttaa havaitsemaan ja ottamaan puheeksi asioita (esim. Kelly 2008). Eron eri ulottuvuuksien ymmärtäminen vaatii ammattilaisilta sekä psykososiaalista että juridista osaamista. Parhaimmillaan eri osaamisalueet yhdistyvät moniammatillissa työryhmissä. Moniammatillisuutta on tärkeää harjoitella jo opiskeluvaiheessa, jotta se sisäistyisi vaikuttavaksi työskentelyorientaatioksi (esim. Kekoni ym. 2019). Sosiaalityön valtakunnallinen yliopistoverkosto Sosnet on linjannut sosiaalityön koulutuksen tavoitteena olevan tuottaa laaja-alaista, tutkimukseen perustuvaa asiantuntijuutta. Sosiaalityöntekijän ydinosaamiseen kuuluu kyky toimia vaativissa ammatillisissa asiakastilanteissa sekä moniammatillisissa verkostoissa asiantuntijana. (Lähteinen ym. 2017.)

Eroauttaminen voi kärjistyneessä konfliktitilanteessa olla kokeneellekin ammattilaiselle kuormittavaa. Tämän vuoksi moniammatillisen tiimin tuki yhdistettynä reflektiiviseen ${ }^{2}$ työotteeseen lisää myös ammattilaisen valmiuksia kohdata palveluita tarvitseva henkilö kokonaisvaltaisemmin. Toimivan moniammatillisen ryhmän avulla työn 
vastuut ja työkuorma saadaan jakautumaan tasaisemmin, mikä lisää työntekijöiden pysyvyyttä ja asiakkaille annettavan palvelun laatua.

\section{VIITTEET}

1 Kelpoisuusvaatimuksena sosiaalihuoltolaissa (1301/2014) tarkoitetun lastenvalvojan 27 a \ tehtävissä voi toimia sosiaalityöntekijä tai henkilö, jolla on muu tehtävään soveltuva ylempi korkeakoulututkinto. Mitä 1 momentissa on säädetty, koskee myös henkilöä, jonka tehtäviin kuuluu vastata lapsen huollosta ja tapaamisoikeudesta annetun lain 8 S:ssä tai lapsen elatuksesta annetun lain 8 \$:ssä tarkoitettujen sopimusten valmistelusta.

2 Reflektiivisellä työotteella tarkoitetaan kykyä sanoittaa sisäistä kokemusta ja nostaa se yhteiseen tarkasteluun. Reflektiivinen työote edistää jaetun ymmärryksen muodostumista. Reflektiivinen työntekijä kykenee tarkastelemaan ja arvioimaan omaa toimintatapaansa suhteessa asiakkaisiin ja yhteistyötahoihin, mikä on tärkeää ammatillisen kehittymisen kannalta. (esim. Burr ym. 2016.)

\section{KIRJALlisuUs}

Amato, Paul (2000) The Consequences of Divorce for Adults and Children. Journal of Marriage and the Family 62 (4), 1269-1287.

Amato, Paul \& Kane, Jennifer \& James, Spencer (2011) Reconsidering the "Good Divorce". Family Relations 60 (5), 511-524. https://doi.org/10.1111/ j.1741-3729.2011.00666.x

Auvinen, Maija (2006) Huoltoriidat tuomioistuimissa. Sosiaalitoimi selvittäjänä, sovittelijana, asiantuntijana. Helsinki: Suomalainen lakimiesyhdistys.

Ballard, Robin H. \& Holtzworth-Munroe, Amy \& Applegate, Amy G. \& D'Onofrio, Brian M. \& Bates, John E. (2013) Randomized Controlled Trial of Child-Informed Mediation. Psychology, Public policy, and Law 19 (3), 271-281. https:// doi.org/10.1037/a0033274

Birditt, Kira S. \& Wan, Wylie H. \& Orbuch, Terri L. \& Antonucci, Tony C. (2017) The Development of Marital Tension: Implications for Divorce Among Married Couples. Developmental Psychology 53 (10), 1995-2006. https://doi. org/10.1037/dev0000379

Bodenmann, Guy \& Charvoz, Linda \& Bradbury, Thomas N. \& Bertoni, Anna \& Lafrate, Raffaella \& Giuliani, Christina. \& Banse, Rainer \& Behling, Jenny (2007) The role of stress in divorce: A three-nation retrospective study. Journal of Social and Personal Relationship 24 (5), 707-728. https://doi. org/10.1177/0265407507081456

Bracke, Piet \& Colman, Elien \& Symoens, Sara \& Van Praag, Lore (2010) Divorce, divorce rates, and professional care seeking for mental health problems in Europe: a cross-sectional population-based study. Public Health 10 (1), 224-235. https://doi.org/10.1186/1471-245810-224

Burr, Viv \& Blyth, Eric \& Sutcliffe, Jamie \& King, Nigel (2016) Encouraging SelfReflection in Social Work Students: Using Personal Construct Methods. British Journal of Social Work 46 (7), $1997-$ 2015. https://doi.org/10.1093/bjsw/ bcw014

Castrén, Anna-Maija (2009) Onko perhettä eron jälkeen? Eroperhe, etäperhe, uusperhe. Helsinki: Gaudeamus.

Cohen, Orna \& Finzi-Dottan, Ricky (2012) Reasons for Divorce and Mental Health Following the Breakup. Journal of Divorce \& Remarriage 53 (8), 581601. https://doi.org/10.1080/10502556 .2012 .719413

Dallam, Stephanie \& Silberg, Joyanna (2016) Recommended treatments for "parental alienation syndrome" (PAS) may cause children foreseeable and lasting psychological harm. Journal of Child Custody 13 (2-3), 134-143. https://doi. org/10.1080/15379418.2016.1219974

Di Stefano, Gessica \& Cyr, Francine (2014) Child Adjustment Following Parental Separation: The Role of Maternal WellBeing, Parental Quality, and Household Income. Journal of Child Custody 11 (1), 
5-24. https://doi.org/10.1080/1537941 8.2014 .892802

Garber, Benjamin (2014) The Cameleon Child: Children as Actors in the High Conflict Divorce Drama. Journal of Child Custody 11 (1), 25-40. https:// doi.org/10.1080/15379418.2014.8928 05

Greenberg, Lyn R. \& Doi Fick, Lynda \& Schnider, Robert (2012) Keeping the Developmental Frame: Child-Centered Conjoint Therapy. Journal of Child Custody 9 (1-2), 39-68. https://doi.org/10.1 080/15379418.2012.652568

Haavisto, Vaula \& Bergman-Pyykkönen, Marina \& Karvinen-Niinikoski, Synnöve (2014) Perheasioiden sovittelun uudet tuulet - havaintoja, mallinnuksia ja arvioita FASPER-hankkeen pohjalta. Helsinki: Suomen sovittelufoorumi ry.

Halila, Ritva \& Kaukonen, Pälvi \& Malja, Marjo \& Savola, Suvi (toim.) (2019). Lasten, nuorten ja perheiden osaamis- ja tukikeskukset. LAPE-muutosohjelmassa tehdyn valmistelutyön loppuraportti. Sosiaali- ja terveysministeriön raportteja ja muistioita 2019:30. Helsinki: Sosiaali- ja terveysministeriö. https://doi. org/10.23990/sa.73002

Halme, Nina \& Vuorisalmi, Merja \& Perälä, Marja-Leena (2014) Tuki, osallisuus ja yhteistoiminta lasten ja perheiden palveluissa. Työntekijöiden näkökulma. Raportti 4/2014. Helsinki: Terveyden ja hyvinvoinnin laitos.

Hautanen, Teija (2017) Vain vanhempien parisuhdeasia? Väkivallan arviointi huoltoriidoissa. Teoksessa Johanna Niemi \& Heini Kainulainen \& Päivi Honkatukia (toim.) Sukupuolistunut väkivalta. Oikeudellinen ja sosiaalinen ongelma. Tampere:Vastapaino, 121-137.

Henriksson, Markus \& Lönnqvist, Jouko (2014) Psyykkiset kriisit, sopeutumishäiriöt ja stressireaktiot. Teoksessa Jouko Lönnqvist \& Markus Henriksson \& Mauri Marttunen \& Timo Partonen (toim.) Psykiatria, 11.uudistettu painos. Helsinki: Duodecim, 350-377.

Häkkänen-Nyholm, Helinä (2010) Lapsen vieraannuttaminen toisesta vanhemmasta erotilanteessa. Duodecim 126, 499-505.

Hämäläinen Juha (2012) Huoltoriidan kallis hinta - eroauttamisen rakenteet ja kustannukset. Teoksessa Sinikka AapolaKari \& Anniina Nivala \& Teea Tonttila (toim.) Nuoren tukeminen vanhempien erotessa - tutkimusnäkökulmia ja hyviä käytäntöjä. Suomen kasvatus- ja perheneuvontaliitto, Helsinki, 14-26.

Isometsä, Erkki (2011) Masennustilan puhkeaminen ja tunnistaminen. Teoksessa Tarja Heiskanen \& Matti Huttunen \& Jyrki Tuulari (toim.) Masennus. Helsinki: Duodecim, 19-24.

Karttunen, Risto (2010) Isän ja äidin välissä. Lapsen kuulemisen psykologinen kehys huolto- ja tapaamisriidoissa. Tampere: Tampereen Yliopistopaino.

Karvinen-Niinikoski, Synnöve \& Pelli, Marja 2010. Perheasioiden sovittelu - riitelykulttuurista vastuulliseen osallisuuteen. Teoksessa Esa Poikela (toim.) Sovittelu. Ristiriitojen kohtaamisesta konfliktien hallintaan. PS-kustannus, Jyväskylä, 91-108.

Kekoni, Taru \& Jaakola, Anne-Mari \& Mönkkönen, Kaarina \& Pehkonen, Aini \& Profiam sosiaalipalvelut Oy:n henkilöstö (2019) Kohti monitoimijaista kehittämistä. Teoksessa Kaarina Mönkkönen \& Taru Kekoni \& Aini Pehkonen (toim.) Moniammatillinen yhteistyö. Vaikuttava vuorovaikutus sosiaali- ja terveysalalla. Helsinki: Gaudeamus, 74-112. https://doi.org/10.23990/sa.70181

Kauppinen, Nina (2013) Eronjälkeinen selviytyminen ja onnistunut yhteistyö eroperheiden tarinoissa. Sosiaalityön erikoistumiskoulutuksen lisensiaatintutkimus. Turku: Turun yliopisto.

Kelly, Joan B. (2008) Preparing for the Parenting Coordination Role: Training Needs for Mental Health and Legal Professionals. Journal of Child Custody 5 (1-2), 140-159. https://doi. org/10.1080/15379410802070476

Kiiski, Jouko (2011) Suomalainen avioero 2000-luvun alussa. Miksi avioliitto puretaan, miten eron koetaan ja miten siitä selviydytään? Joensuu: Itä-Suomen yliopisto.

Kohti lapsi- ja perhelähtöisiä palveluita (2019). Helsinki: Sosiaali- ja terveysministeriö. https://stm.fi/ documents/1271139/1953486/LAPEesite-verkko.pdf/68a59997-cc83-406dac8a-3dd8fbb5f3ba Luettu 15.2.2019. 
Laki lapsen huollosta ja tapaamisoikeudesta 8.4.1983/361.

Laki lapsen huollosta ja tapaamisoikeudesta annetun lain muuttamisesta 8.2.2019/190.

Laki sosiaalihuollon ammattihenkilöistä 26.6.2015/817.

Lapsen paras etusijalle eropalveluissa (2010). Lapsiasiainvaltuutetun toimiston julkaisuja 2010:4. Jyväskylä: Lapsiasiainvaltuuteun toimisto.

Luoma, Ilona \& Aronen, Eeva (2016) Huoltajuuskiistat ja vanhemmuuden arviointi. Teoksessa Kirsti Kumpulainen \& Eeva Aronen \& Hanna Ebeling \& Eila Laukkanen \& Mauri Marttunen \& Kaija Puura \& Andre Sourander (toim.) Lastenpsykiatria ja nuorisopsykiatria, 1.painos. Helsinki: Duodecim, 737-740.

Lähteinen, Sanna \& Raitakari, Suvi \& Hänninen, Kaija \& Kaittila, Anniina \& Kekoni, Taru \& Krok, Suvi \& Skaffari, Pia (2017) Sosiaalityön koulutuksen tuottama osaaminen. Sosnet julkaisuja 7. Rovaniemi:Valtakunnallinen sosiaalityön yliopistoverkosto Sosnet.

Nikupeteri, Anna \& Tervonen, Harriet \& Laitinen, Merja (2015) Eroded, Lost or Reconstructed? Security in Finnish Children's Experience of Post-Separation Stalking. Child Abuse 24 (4), 285296. https://doi.org/10.1002/car.2411

O’Donohue, William \& Benuto, Lorraine T. \& Bennett, Natalie (2016) Examing the validity of parental alienation syndrome. Journal of Child Custody 13 (23), 113-125. https://doi.org/10.1080/1 5379418.2016.1217758

OM, Oikeusministeriö (47/2017) Lapsenhuoltolain uudistaminen. Työryhmän mietintö. Helsinki: Oikeusministeriö. http://julkaisut.valtioneuvosto.fi/ bistream/handle/10024/80751/OMML 47 2017 Lapsenhuolto.pdf Luettu 20.8.2018.
OM, Oikeusministeriö (11/2018) Tuomioistuinten työtilastoja vuodelta 2017. Helsinki: Oikeusministeriö. Saatavilla http://julkaisut.valtioneuvosto.fi/handle/10024/160698. Luettu 13.3.2019.

Piispa, Minna \& Taskinen, Jukka \& Ewalds, Helena (2012). Selvitys perhe- ja lapsensurmien taustoista vuosilta 2003-2012. Helsinki: Sisäasiainministeriö.

Sbarra, D.A. \& Hasselmo, K. \& Bourassa K.J. (2015) Divorce and Health: Beyond Individual Differencecs. Current Directions in Psychological Science 24 (2), 109-113. https://doi. org $/ 10.1177 / 0963721414559125$

Socialstyrelsen (2012) Vårdnad, boende och umgänge. Handbok - stöd för rättstillämpning och handläggning inom socialtjänstens familjerätt. Stockholm: Socialstyrelsen.

Sosiaalihuoltolaki 30.12.2014/1301.

SVT, Suomen virallinen tilasto. Väestö 2017. Perheet 2016. Helsinki:Tilastokeskus. https://www.stat.fi/til/perh/2016/ perh_2016_2017-05-26_tie_001_ fi.html Luettu 5.3.2018.

SVT, Suomen virallinen tilasto. Väestö 2018. Siviilisäädyn muutokset 2017. https://www.stat.fi/til/ssaaty/2017/ ssaaty_2017_2018-05-08_fi.pdf Luettu 6.3.2019.

Symoens, Sara \& Van de Velde, Sarah \& Colman, Elien \& Bracke, Piet (2014) Divorce and the Multidimensionality of Men and Women's Mental Health: The Role of Social-Relational and SocioEconomic Conditions. Applied Research Quality Life 9 (2), 197-214. https://doi. org/10.1007/s11482-013-9239-5 